\title{
Las integraciones económicas supraestales y los acuerdos entre bloques económicos, en definitiva, la globalización como último embate al concepto racional normativo de constitución ${ }^{1}$
}

\author{
José Luis García Guerrero*
}

\section{INTRODUCCIÓN}

La Organización Mundial del Comercio (OMC), los países emergentes o la globalización parecen, en principio, cuestiones ajenas a la ciencia constitucional. En todo caso ha habido ciertas referencias a una globalización del Derecho Constitucional, aunque en español me parezca más precisa la expresión universalización, dado que universalizar significa: "Hacer universal algo, generalizarlo mucho".

Es cierto que en la actualidad la inmensa mayoría de los países democráticos presentan un Derecho constitucional semejante o análogo en su mayor parte, probablemente entre un cincuenta o sesenta del mismo, lo que no deja de ser una consecuencia del triunfo apoteósico del concepto racional normativo de Constitución y, en muy directa relación, del poderoso influjo de los Estados Unidos de América en todo el mundo y en Europa, especialmente tras la II Guerra Mundial, lo que ha sido insuficientemente estudiado. La similitud de este bloque de Derecho Constitucional es evidente, piénsese en los principales órganos constitucionales, parlamento, gobierno, administración y poder judicial, en la estructura y funciones de éstos; en los valores y principios constitucionalizados $y$ en el caso de alguno de estos en su concreción como derechos y libertades fundamentales, así como en sus mecanismos de protección, nacionales e

Doctorado em Derecho Constitucional - Universidad de Castilla-La Mancha (1993). Diretor maestrado bianual - Universidad Catolica Madre Y Maestra e professor titular - Universidad de Castilla-La Mancha. 
internaciones, contribuyendo estos últimos a la referida homogeneización; piénsese, por último pero sin ánimo exhaustivo, en la teoría constitucional, en la interpretación o en el tronco de las fuentes del derecho y en la generalizada admisión de las normas constitucionales, legales y reglamentarias.

El treinta y cinco o cuarenta y cinco por ciento del Derecho Constitucional no es diferente en cada estado, simplemente, frente a la uniformidad compartida que se acaba de describir, ahora se puede elegir entre diferentes modelos que no comparten todos los países sino bloques de éstos en virtud de una opción escogida por el poder constituyente que trata de esta forma de mantener el vínculo entre el modelo constitucional y la forma de ser permanente de cada pueblo. Entre los más relevantes están los sistemas de civil law frente a la opción anglosajona del commowlaw; enlajefaturadelestado, puedeescogerseentrela forma presidencialista y parlamentaria, ya sea esta última república o monarquía; tras acogerse en la mayor parte del mundo el valor democrático, su principio democrático se realiza políticamente a través de la democracia representativa liberal, y jurídicamente mediante la democracia representativa de partidos, los institutos de democracia directa son especialmente para este último sistema un incoherente complemento más o menos utilizado y la denominada democracia participativa es más bien un nombre desprovisto de contenido más allá de la revocatoria, que, por cierto, sólo resulta coherente en modelos de democracia representativa liberal, nunca en la de partidos; la mayor o menor descentralización del poder permite a los países escoger entre el modelo unitario, regional o federal; la generalizada aceptación del tránsito del estado de derecho al estado constitucional de derecho agrupa a los estados en sistemas de justicia constitucional difusos o concentrados, abriéndose paso en Iberoamérica cada vez con más fuerza un sistema hibrido; finalmente, y nuevamente sin ánimo exhaustivo, en la opción por el Estado Social frente al Liberal, especialmente en Europa, lo que se ha concretado en derechos constitucionales de prestación y en mandatos a los poderes públicos, que no sólo tropiezan, como en este escrito se va a señalar, con dificultades económicas sino con el error dogmático de pretender concebirlos como fundamentales, lo que lejos de fortalecerlos los debilita profundamente al impedir el desarrollo de una teoría jurídica que facilite su consecución efectiva al tiempo que contribuye a la deslegitimación del sistema. A este fenómeno, que se acrecienta progresivamente con el paso del tiempo, es a lo que me refiero cuando hablo de una universalización del derecho constitucional, que otros denominan en español globalización, y que fácilmente puede observarse leyendo los trabajos de la mejor literatura jurídica italiana comparatista.

El Derecho Constitucional singular o específico de un estado, salvo llamativas excepciones, apenas ocupa actualmente un cinco o diez por ciento. A modo de ejemplo puede verse en España la creación del estado autonómico frente al federal, la diputación permanente en lugar de la prorrogatio o las leyes orgánicas, recientemente incorporadas por República Dominicana; en Francia su sistema presidencial con la equivocidad de su parlamentarismo, o el sostenimiento del 
Consejo Constitucional francés frente a la generalizada adopción de la justicia constitucional; por acabar con algunos ejemplos, en el Reino Unido perviven el carácter no escrito de su Constitución y el sostenimiento del sistema electoral mayoritario de circunscripción uninominal frente a los proporcionales, propios de los modelos de democracia representativa de partidos, aunque curiosamente este factor ha facilitado un mayor grado de democracia interna en los partidos británicos.

No obstante, no es objeto de este trabajo la interesante universalización del Derecho Constitucional sino cómo la denominada globalización está incidiendo y poniendo en peligro a elementos sustanciales del Derecho Constitucional. Se quiere examinar a modo de hipótesis si las integraciones supraestatales, los acuerdos entre bloques económicos, en definitiva la globalización suponen el último embate de los muchos que ha sufrido al concepto racional normativo de ConstituciónMás precisamente si la soberanía popular, el principio democrático ylas constituciones económicas intervencionistas nacionales seriamente afectados por las integraciones económicas supraestatales, especialmente en sus fases más avanzadas, como la europea, se ven todavía más alterados o, mejor aún, desustancializados por la última fase de la globalización: los acuerdos entre bloques económicos; lo que está afectando además, en la Integración Euro, que se toma como ejemplo, a los principales principios y valores constitucionales, a la autonomía presupuestaria, poniendo en peligro el Estado Social y sus más relevantes concreciones como los derechos sociales y los mandatos a los poderes públicos, en la medida en que éstos requieren de una cierta capacidad económica para su realización; y ello por no hablar de un sistema tributario justo inspirado en los principios de igualdad y progresividad. No es descabellado pensar que la carga deslegitimatoria que todo esto conlleva, de ser acertada la hipótesis del trabajo, que requerían de un trabajo interdisciplinar para su confirmación, puede poner en peligro la propia subsistencia de estos sistemas constitucionales, al menos, en la forma en que los conocemos. El escrito, como se acaba de indicar, es más una hipótesis de trabajo que una certidumbre científica. Se afronta desde la óptica del Derecho Constitucional, pero, como en otras ocasiones, necesita algo más que un apoyo auxiliar de otras ciencias, especialmente de la económica y, en menor media, de la política, de la estadística y de la sociología.

La mundialización o universalización del Derecho Constitucional responde a una tendencia a la que parece no escapar ninguna manifestación humana. Se ha producido en el cine, en el urbanismo, piénsese en la generalización de las unifamiliares anglosajonas con sus centros comerciales frente al concepto de ciudad mediterránea, en la comida, en las nuevas tecnologías, en la ropa, etc. Lo mismo sucede en el campo económico, donde, sin embargo, el fenómeno ha merecido que el Diccionario de la Real Academia de la Lengua Española emplee un término específico: globalización, que significa "Tendencia de los mercados y las empresas a extenderse alcanzando una dimensión mundial que sobrepasa 
las fronteras nacionales". Ahora bien, curiosamente, para comenzar a entender el término globalización es necesario atender al concepto de constitución.

\section{EL CAPITALISMO Y LA CONSTITUCIÓN RACIONAL NORMATIVA}

Con excesiva frecuencia los constitucionalistas vinculan el origen de la Constitución liberal, denominada técnicamente racional normativa, con la finalidad de preservar los derechos y libertades fundamentales; esto es, ámbitos de libertad del individuo inmunes frente a la acción del poder político. El sometimiento del poder político a las leyes, es decir, el Estado de Derecho; la participación de los ciudadanos en la configuración de los órganos constitucionales y en el proceso de conformación de la voluntad estatal; así como la separación de poderes, para un cierto entendimiento liberal, no eran otra cosa que la forma más efectiva de preservar los derechos y libertades.

En el contexto que se acaba de expresar la propiedad privada, que también engloba la propiedad de los medios de producción, o, lo que es lo mismo, la libertad de empresa, ya se constitucionalice individualizada o conjuntamente; no eran otra cosa que un derecho y una libertad que las Cartas Constitucionales debían garantizar, junto a la libertad de expresión, de culto, reunión, entre otros muchos. Éste sería el entendimiento clásico para explicar la aparición del concepto liberal de constitución, y su supervivencia durante más de dos siglos a pesar de los numerosos embates teóricos y empíricos que ha sufrido.

Frente a esta tesis clásica, yo creo en una antítesis, cuyos elementos esenciales esbozo Weber en su momento, menos candorosa y utópica a propósito del origen y triunfo de las constituciones liberales. La aparición y pervivencia del concepto racional normativo de Constitución se debe a que estas normas constituyen el marco jurídico en que más cómodamente puede instalarse y desarrollarse el sistema económico capitalista.

En el antiguo régimen europeo no podía funcionar un sistema capitalista. Las propiedades, inmuebles, muebles, empresas y relaciones económicas no podían quedar al arbitrio del Monarca absoluto. El sistema capitalista necesitaba la seguridad jurídica aportada por el Estado de Derecho. Era imprescindible que se determinara previamente quién elaboraba las normas con incidencia en el campo económico y a través de qué procedimientos, así como quién controlaba el sometimiento del poder a esas normas. Que se pudiera conocer anticipadamente las consecuencias jurídicas de una determinada acción u omisión. Finalmente, era conveniente reservar un ámbito inmune de intervenciones frente al poder político en torno a los derechos de propiedad y empresa.

En garantía de todos estos extremos requeridos por el sistema capitalista se arbitra la participación de la burguesía en los órganos constitucionales y en la 
conformación de su voluntad; la separación de poderes; el Estado de Derecho; y la diferenciación entre poder constituyente y constituido. En definitiva, la constitución liberal no triunfaba, únicamente, por su afirmación del principio democrático, ni por la preservación de los derechos y libertades fundamentales; sino, fundamentalmente y con toda probabilidad, por crear las condiciones y garantías para el más adecuado funcionamiento del sistema capitalista.

A final del siglo XIX y principios del XX, con el triunfo de la tesis y el olvido de la antítesis, surge en Alemania la expresión constitución económica, que pronto disfrutará de gran predicamento en todo el mundo. Con este término se olvida la antítesis y se restringe su ámbito; se ignora que el propio concepto liberal de Constitución responde a una necesidad económica, por lo que definir a la constitución económica, tal y como hacen numerosos autores, como el conjunto de normas constitucionales que hacen referencia a la estructura y funcionamiento de la actividad económica es una conceptualización restrictiva, que pierde buena parte de su esencia; ya que es precisamente la economía la razón de ser de la Constitución liberal.

No obstante, alguna doctrina ha definido a la Constitución económica como el marco jurídico fundamental de la estructura y funcionamiento de la actividad económica. Este concepto mejora notablemente, aunque sigue siendo restrictivo; pero para evitar confusiones terminológicas se va a adoptar aquí. Ahora bien, por constitución económica se entenderá, de una parte, el conjunto de normas referidas directa e indirectamente a la economía; y, de otra parte, otros preceptos, principios y valores, que, aparentemente, nada tienen que ver con la economía, pero que, en realidad, influyen poderosamente en la misma. Como se ha defendido en la antítesis, la Constitución racional normativa triunfa y se consolida por responder a las necesidades del sistema capitalista y lleva inserta sus genes. Como ahora se verá, la definición del Estado Social afecta en gran medida al campo económico, al punto de instaurar un sistema neocapitalista, cuando no fuertemente intervencionista.

Con esta precisión terminológica, voy a utilizar el concepto de constitución económica y diferenciar distintos modelos, incluso, alguno de ellos, incompatible o, más bien, antagónico con el propio concepto racional normativo de Constitución. Aquí, se esbozarán someramente tres.

\section{LA CONSTITUCIÓN ECONÓMICA. LOS DIFERENTES MODELOS: LIBERAL, MARXISTA E INTERVENCIONISTA}

\subsection{La constitución económica liberal}

La constitución económica originaria responde al modelo liberal que mantiene una rígida separación entre el Estado y la Sociedad. En este contexto 
la intervención estatal debe ser tan reducida como sea posible. En orden a su aseguramiento se establece la garantía institucional del mercado.

Los poderes públicos y muy especialmente el legislativo deben de garantizar que el mercado funciona en condiciones de economicidad, esto es, ha de asegurarse la igualdad entre todos los agentes económicos y la libre competencia entre los mismos. Las decisiones de las unidades económicas y su comportamiento no pueden basarse en decisiones tomadas por los poderes públicos, sino que deben orientarse al beneficio económico. Con estas premisas, el mercado, a través de las reglas de la oferta y la demanda, determina el comportamiento de las unidades económicas.

El Estado Liberal afirma la unidad económica nacional y su correlato, la unidad de mercado, que implica, de una parte, la libertad de circulación de capitales, servicios, mercancías y mano de obra; y, de otra, la igualdad en las condiciones básicas de ejercicio de la actividad económica.

La constitución económica liberal, por tanto, reduce el papel del Estado a garantizar la igualdad en el ejercicio de la actividad económica, la libertad de circulación, y la ausencia de perturbaciones tanto internas como externas. Este tipo de Constitución protege a la Sociedad Civil mediante la garantía institucional del mercado y los derechos fundamentales a la propiedad privada y la libertad de empresa.

La garantía institucional del mercado implica que los poderes públicos, y muy especialmente el legislativo, deben de respetar la imagen maestra o LeitBild del mercado. No se trata de la garantía institucional de instituciones políticas o administrativas, sino de garantías de instituto que protegen a determinada instituciones civiles o figuras de derecho privado. La protección se articula frente al poder público y muy especialmente respecto al poder legislativo; éste en su intervención reguladora no puede suprimir, desfigurar o vaciar de contenido los rasgos maestros o esenciales del mercado.

El reconocimiento de la propiedad privada se extiende a la de los medios de producción; no obstante, con buen criterio la Constitución Dominicana, como en la mayor parte de los países, ha reconocido independientemente la propiedad privada de los medios de producción, esto es, la libertad de empresa, que conlleva la libre iniciativa privada. Al igual que en el caso del mercado, se está en presencia de ámbitos de libertad privados, inmunes, en cuanto sea posible, a la acción de los poderes públicos; éstos deben de respetar el contenido esencial de estos derechos, derechos de libertad, configurados por su titular y con una intervención en su régimen jurídico de los poderes públicos muy restringida, concretamente, medidas limitativas destinadas a compatibilizar su ejercicio con otros derechos o bienes constitucionales, y asegurar su disfrute simultáneo por múltiples titulares; así como medidas tuitivas, destinadas a la protección de estos derechos. 


\subsection{Ia constitución económica marxista}

La constitución económica marxista niega el mercado como instrumento más eficiente para la asignación de recursos, las leyes de la oferta y la demanda, así como la propiedad privada y la libertad de empresa.

Esta constitución basa las decisiones de los agentes económicos en la asignación de objetivos por parte de los poderes públicos, fundamentalmente, a través de la planificación. Al tiempo que niega la libertad de empresa, establece la iniciativa pública económica de forma exclusiva. Sus profundas deficiencias y el descenso acusado de la productividad por falta de incentivos a los agentes económicos originó su derrota frente al modelo liberal y neoliberal, así como su progresivo abandono por la mayor parte de los Estados, por lo que no merece la pena extenderse aquí mucho más al respecto.

\subsection{La constitución económica intervencionista}

En mi opinión, en la mayor parte de los países europeos, con un contexto de guerra fría y para hacer frente ideológicamente a las constituciones económicas marxistas, se produce el tránsito del Estado liberal democrático de derecho al Estado social democrático y constitucional de derecho.

El Estado Social no confía en el mercado como único instrumento para lograr una más justa y eficiente asignación de recursos, por lo que habilita instrumentos de intervención de los poderes públicos sobre el mercado. Se trata de una intervención del Estado en la Sociedad, a través de medidas determinadas democráticamente, pero sin negar las garantías propias del derecho, tal y como Abendrothseñaló, ésta es la forma de interrelacionar el Estado Social, de Derecho y Democrático. En definitiva, no se confía en la Sociedad como orden autónomo, es necesaria una intervención para corregir sus deficiencias.

Con estos presupuestos se reconoce mediante una garantía institucional el mercado y a través de un derecho constitucional, la libertad de empresa; ahora bien, la garantía de su ejercicio y la defensa de la productividad se restringen de acuerdo con las exigencias de la economía general y, en su caso, de la planificación. La propiedad privada también se reconoce como derecho constitucional, pero con una importante limitación en su contenido debido a la función social que debe desempeñar. La propiedad privada no sólo sería un derecho de uso y señorío, sino que debe cumplir una importante función social, que puede en determinados casos llevar a determinar su propio contenido. Por ello, el profesor Rubio Llorente ha llegado a señalar que más que en presencia de un derecho fundamental se está ante un derecho subjetivo debilitado, que se asemeja más a una garantía institucional. 
Como claramente se aprecia, se contemplan en esta constitución económica intervencionista los elementos de la liberal, aunque fuertemente debilitados. El mercado es una garantía de instituto; la propiedad privada, como se ha visto, en un cierto sentido, también; y la libertad de empresa se reconoce como derecho constitucional. Así, hay Constituciones que, como en mi opinión sucede con la española de 1978, no reconocen la libertad de empresa y el derecho a la propiedad privada como fundamentales, sino como simples derechos constitucionales, que carecen de importantes garantías normativas y jurisdiccionales otorgados a aquéllos. No disfrutan de la protección jurisdiccional preferente y sumaria contemplada en el artículo 53.2, ni del recurso de amparo constitucional; tampoco tienen importantes garantías normativas como son la reserva impropia de ley orgánica y la especial rigidez, a través de procedimiento de modificación agravado, frente a la reforma constitucional. La misma senda creo que sigue la Constitución dominicana de 2010.

La constitución económica intervencionista se diferencia de la liberal, no sólo por la diferente conceptuación del mercado, propiedad privada y libertad de empresa, que se acaban de reseñar; sino, principalmente, por introducir importantes mecanismos a través de los cuales los poderes públicos interfieren en el mercado. A continuación, se van a sintetizar brevemente.

Se prevé la aprobación por el gobierno de proyectos de planificación con la colaboración de otros entes territoriales y el asesoramiento de Consejos Económicos y Sociales, en donde participan sindicatos, organizaciones profesionales y empresariales, así como otras organizaciones de la sociedad civil. Se establece la iniciativa pública económica que coexiste con la privada y aunque reduce el espacio de ésta debe desarrollarse en condiciones de igualdad y libre competencia. Se contempla, asimismo, la reserva al sector público, mediante ley, de recursos o servicios esenciales, especialmente en casos de monopolio, y la intervención de empresas; así como se establece, en vía de principio, la subordinación de toda la riqueza del país al interés general. Finalmente, se establecen mecanismos de participación de los trabajadores en la dirección de las empresas -los sindicatos nombran a cualificados expertos económicos y juristas que se integran en los consejos de administración de las empresas-, haciendo compatible los derechos del propietario con los de los trabajadores, que hacen productiva la propiedad, tal y como señalaba el profesor García Pelayo.

\section{LA PRIMERA FASE DE LA GLOBALIZACIÓN: LOS ACUERDOS DE INTEGRACIÓN SUPRAESTATAL}

La ineficiencia de las constituciones económicas marxistas y su baja productividad llevó a su abandono en la mayor parte de los países, como se ha reseñado supra, y al colapso en su propio corazón europeo plasmado reveladoramente con la caída del muro de Berlín en 1989.La lógica llevaba a pensar 
en dos hipótesis: una coexistencia pacífica entre los dos modelos de constitución económica triunfantes o un enfrentamiento entre ambas por la hegemonía mundial. La segunda parecía más razonable si se piensa que la constitución económica intervencionista, lógico correlato del Estado Social, quizá no era tanto un triunfo de la fuerzas sindicales, democratacristianas y socialdemócratas como una concesión de los agentes económicos en el tablero de ajedrez de la guerra fría. Se trataba de combatir a la constitución económica marxista, de evitar que países occidentales pudieran sentir la tentación de un cambio de bando. Así se pensaba cuando en dos mil cinco se elaboró el papel "Integración económica y reforma constitucional” y que sirve de soporte a éste.

Actualmente cabe considerar que las dos hipótesis del párrafo anterior sean incorrectas. Quizás está surgiendo un nuevo orden económico internacional pos-capitalista que está poniendo en jaque a las dos constituciones económicas sobrevivientes; un orden ultra liberal, al menos, si se contempla desde Europa o, incluso, Estados Unidos. En una primera fase se produjo una desconstitucionalización de las constituciones intervencionistas en Europa al hilo de la integración económica supraestatal más intensa que se ha conocido. Sin que haya finalizado la primera asistimos a una segunda desconstitucionalización o más bien a un embate en todo regla al concepto racional normativo de constitución originado por los acuerdos -o sus preparativos- entre integraciones económicas o entre éstas y las mayores economías del mundo. La globalización está detrás de ambas fenómenos, en realidad son dos fases de la misma.

Prácticamente al tiempo de la caída del muro de Berlín y del desmoronamiento de las constituciones marxistas europeas, los agentes económicos empezaron a encontrarse incomodos en el corsé de las dos constituciones económicas sobrevivientes, especialmente con la unidad económica nacional y su correlato la unidad de mercado y buscaron su superación mediante la globalización. La Organización Mundial del Comercio (OMC), siguiendo a estos agentes económicos, persiguió la liberación multilateral del comercio, pero tras su fracaso promovió decididamente las integraciones económicas supraestatales que consiguen, en una primera fase, en un ámbito territorial más reducido el mismo objetivo. En dos mil cinco había ya más de dos cientos veinte acuerdos de integración. Ahora bien, no todas las integraciones son iguales ni presentan las mismas consecuencias constitucionales.

\subsection{LOS DIFERENTES TIPOS DE ACUERDOS DE INTEGRACIÓN ECONÓMICA SUPRAESTATAL Y LAS PRIMERAS CONSECUENCIAS CONSTITUCIONALES.}

Para la ciencia económica existen, según la opinión más extendida, al menos, cuatro tipos de acuerdos supraestales dependiendo de la intensidad 
de su integración económica. Al hilo de su explicitación se tratará de extraer consecuencias constitucionales.

El primer tipo son los acuerdos de libre comercio que encuentran un contexto favorable en el fin de la guerra fría y en el fracaso de la liberalización multilateral, que encontró una favorable alternativa en los acuerdos de integración regional. $\mathrm{Su}$ triunfo viene marcado por el reconocimiento de que los modelos de sustitución de importaciones, que implicaban el cierre de fronteras, no estaba generando las altas tasas de crecimiento económico de las últimas décadas; y por las grandes ventajas que se obtienen de la especialización en ciertos industrias y bienes e, incluso, en sectores de dichas industrias, lo que incrementa las economías de escala con la posibilidad de empleos mejor remunerados, al aumentar el volumen de producción y reducirse el precio de los productos.

Los acuerdos de este tipo se caracterizan por la reducción, cuando no eliminación, de las barreras arancelarias a los productos comerciales. Se persigue la libre circulación de mercancías y, en la medida de lo posible, de servicios.

A pesar de algunas opiniones contrarias, esta incipiente fase de integración afecta al principio de unidad económica nacional y su correlato la unidad de mercado. Completada la zona de libre comercio, el mercado de mercancías y, en menor medida, el de servicios se corresponde con el ámbito territorial de la integración económica supraestatal. Ciertas potestades ejecutivas $y$, en menor medida, legislativas y judiciales resultan limitadas. El control efectivo del legislativo sobre el ejecutivo resulta restringido también en este ámbito; pocas responsabilidades directas pueden exigirse a un ejecutivo que está limitado por los acuerdos y consensos que logra alcanzar con otros muchos gobiernos.

El tipo siguiente son las conocidas uniones aduaneras, que se relacionan con el nivel o profundización de la integración; además, de reducirse o, más bien, eliminarse los aranceles entre los estados contratantes y de fijar unos comunes frente al exterior, se busca una política comercial común.

En la unión aduanera las consecuencias constitucionales anteriores se intensifican; buena parte de la política comercial queda en manos de los acuerdos supraestatales, sustrayéndose este ámbito del campo de juego político. Cuando se decide dirigir la unión aduanera hacia un mercado común, el acuerdo de integración económica supraestatal se convierte en derecho primario, del que surgirá un derecho derivado. Se ceden competencias soberanas de naturaleza legislativa, ejecutiva y judicial a órganos supraestatales creados por el acuerdo internacional. Aparecen poderes ejecutivos, legislativos y judiciales propios de la organización supraestatal; la diferenciación entre poder constituyente y constituido, la soberanía popular y el principio democrático comienzan a resultar afectados.

El tercer tipo es el mercado común, que implica una política comercial común y una completa liberalización de los factores de producción, es decir, la 
libre circulación de mercancías, servicios, capitales y mano de obra; se requiere, además, igualdad en las condiciones básicas de ejercicio de la actividad económica.

Una vez consolidada esta fase se producen las mismas consecuencias y dificultades constitucionales, que como se acaba de reseñar, surgen en el propio proceso de construcción del mercado común, esto es, hay un nuevo ordenamiento supraestatal que se relaciona con los ordenamientos de los estados miembros principalmente a través del principio de competencia. El mercado común tiene órganos ejecutivos, legislativos y judiciales propios. La unidad de mercado nacional se ha transformado en unidad de mercado transnacional. Los estados participantes han cedido importantes competencias soberanas y el principio democrático tiene dificultades para operar plenamente.

Por último, el cuarto tipo, que a mi juicio cabría denominar de unidad económica supraestatal conlleva las mismas exigencias que el mercado común, pero incluye, además, una armonización de las políticas macroeconómicas y de las políticas regulatorias. Esta fase sólo se ha alcanzado en la Unión Europea hasta el momento. No obstante, un grupo de países consensuó llegar más lejos y crear una moneda única y un Banco Central Europeo. El acceso de cualquier Estado a la divisa única exige un déficit público no superior al tres por ciento, que la deuda no supera el sesenta por ciento del PIB y un diferencial de inflación del uno coma cinco. Puede afirmarse que se ha producido plenamente una desconstitucionalización de las constituciones económicas de los estados. La economía viene regida por los tratados que ratifican los estados miembros que contemplan exhaustivamente la regulación del orden económico. A esta etapa la denominaremos Integración Euro y al ser la más avanzada la utilizaremos como ejemplo de la segunda fase de la globalización: los acuerdos entre bloques económicos; así como las ventajas e inconvenientes que ésta presenta y las posibilidades de superar éstos.

En un plano constitucional más general el ordenamiento de la Integración Euro se ha convertido materialmente en una constitución, aunque no lo sea formalmente, lo que origina importantes problemas a la diferenciación entre poder constituyente y constituido, a la soberanía y al principio democrático. Desde una perspectiva de la distribución territorial del poder nos encontramos con una forma a caballo entre la Confederación y el Estado Federal, aunque mucho más cerca de esta última forma y la misma carece de legitimidad democrática de origen y de ejercicio.

El único caso conocido, hasta el momento de este cuarto tipo de integración es la Unión Europea, más en concreto la de los países del club euro. El Mercado Común Centroaméricano, el CARICOM, Mercosur y el Pacto Andino cabe definirlos como integraciones del segundo tipo, es decir, uniones aduaneras; las dos últimas organizaciones se dirigían decididamente a la constitución de un mercado común, fase que sólo se alcanzó y superó en Europa. No obstante, desde dos mil cinco el Pacto ha fracasado especialmente tras la Alianza del Pacífico 
(México, Colombia, Perú y Chile) mientras que cobra fuerza Mercosur, al que recientemente se ha incorporado Venezuela.

\subsection{Los diferentes tipos de constitución económica y de acuerdos de integración originan consecuencias constitucionales variables.}

Como se ha visto en los apartados anteriores, hay diferentes modelos de constituciones económicas y diversos tipos de integraciones económicas supraestatales; por tanto, no puede decirse que toda integración económica genere una limitación sobre la constitución económica.

En este campo, yo creo que pueden extraerse dos reglas generales: se puede sostener que a mayor sintonía ideológica entre la integración económica y las constituciones económicas de los estados parte, menores limitaciones sufrirán éstas; y se puede asegurar, también, que a medida que se intensifique la integración económica se incrementarán las limitaciones que sufran las constituciones económicas, lo que se incrementará exponencialmente cuando éstas no coinciden ideológicamente con aquélla.

Las constituciones económicas marxistas sólo pueden integrarse entre ellas, ya se trate de una zona de libre comercio, unión aduanera, mercado común, o una unidad económica supraestatal.

Las constituciones económicas liberales no presentan dificultades para generar una integración económica supraestatal entre ellas, ya se trate de la menos intensa, zona de libre comercio, o de la máxima, unidad económica supraestatal.

Lo mismo cabría decir de las constituciones económicas intervencionistas entre ellas. La dificultad surge cuando se trata de crear una integración económica supraestatal de ideología liberal y todos los estados o, al menos, algunos de ellos tienen constituciones económicas intervencionistas. Los problemas se incrementan a medida que se profundiza en la integración económica; en la fase de libre comercio o, incluso, unión aduanera, las dificultades son menores, pero cuando se llega al mercado común y, especialmente, a la unidad económica supraestatal las dificultades se intensifican.

Estas dificultades surgen por la propia singularidad de las normas constitucionales, frente a los restantes preceptos del resto del ordenamiento jurídico. Éstos se caracterizan por buscar que el supuesto de hecho se ajuste en la mayor medida posible a la consecuencia jurídica, buscan reducir el campo de la interpretación para garantizar la seguridad jurídica. En cambio, la mayor parte de las normas constitucionales son abiertas, deben hacer posible un amplio abanico de interpretaciones, para de esta forma, permitir que las distintas fuerzas políticas puedan aplicar sus propias políticas; buena parte de las normas constitucionales deben de garantizar el pluralismo político, esto es, que partidos políticos con 
diferentes ideologías puedan aplicar sus propios programas de gobierno con unas mismas normas constitucionales.

Las constituciones económicas intervencionistas no sólo permiten políticas neoliberales, sino también políticas económicas de un cierto liberalismo; e, incluso, aplicar políticas muy cercanas al marxismo. Con estos presupuestos una misma constitución económica posibilita gobiernos de orientación conservadora, liberal, neoliberal, democratacristiana y del socialismo democrático.

Cuando se crean integraciones económicas supraestatales de ideología liberal las normas que constituyen el acuerdo suelen impedir a las partes contratantes la aplicación de políticas económicas conservadoras, neoliberales y fuertemente intervencionistas. A medida que se profundiza en la integración, sobre todo en las fases de mercado común y unidad económica supraestatal, se hace más difícil la aplicación de políticas económicas que no respondan al liberalismo; hasta que llega un punto en que las mismas se hacen imposibles. Esto conlleva una hibernación de las normas constitucionales y de aquellas interpretaciones de las mismas que permiten las políticas conservadoras, neoliberales y fuertemente intervencionistas; se reduce el pluralismo político en el campo económico. Los acuerdos de integración no son inconstitucionales porque cualquier partido político que acceda al parlamento y se vea imposibilitado de aplicar su ideario por el acuerdo económico, puede denunciarlo, hacerle perder su eficacia jurídica y, a continuación, aplicar su política económica. No obstante, esto es fácil en las primeras fases de integración económica, zona de libre comercio o unión aduanera (El Pacto Andino ha permitido comprobarlo), y mucho más complicado cuando se profundiza en la integración, mercado común o unidad económica supraestatal (El único caso es la Unión Europea y no hay experiencias al respecto). Por ello, en estos casos, aunque no haya inconstitucionalidad se debe exigir un alto rango jerárquico a la norma que apruebe estas fases de la integración y el máximo consenso posible entre las diferentes fuerzas políticas.

Por tanto, un acuerdo de integración económica supraestatal de inspiración liberal origina a medida que se profundiza en la integración una hibernación o suspensión temporal de la aplicabilidad de las normas constitucionales ideológicamente contrarias. Estos preceptos constitucionales quedan en hibernación mientras esté vigente el acuerdo de integración y sólo tras su denuncia recuperan su plena efectividad.

La experiencia histórica confirma algunas de las afirmaciones realizadas hasta ahora. En un principio no existían interferencias destacadas entre los procesos de integración económica y las constituciones económicas. Esto se debía a la poca intensidad de la integración económica, y a la profunda sintonía ideológica entre la integración y la constitución económica de los estados participantes. Las marxistas encontraban un cauce adecuado en el COMECON y lo mismo, aunque con alguna prevención, cabría predicar del Mercado Común Europeo, creado en un entorno de constituciones económicas intervencionistas. 
Éste a finales de los sesenta no dejaba de ser una unión aduanera con política comercial común y libre circulación de mercancías; y con una gran sintonía entre la ideología de la integración económica y las constituciones económicas de los estados participantes, que respondían al modelo intervencionista; no obstante, ya se observaba alguna distorsión en el horizonte como la prohibición de monopolios.

Más adelante el panorama iba a cambiar radicalmente. La derrota de las constituciones económicas marxistas frente a las constituciones económicas liberales y neoliberales no sólo significó el final de aquéllas, sino también una amenaza frente a las propias constituciones económicas intervencionistas. El capitalismo triunfante, a principios de los años noventa del siglo pasado, encontró en las integraciones económicas supraestatales una importante vía para imponer su ideología liberal, profundizar en la separación entre el Estado y la Sociedad, y restringir las intervenciones de los poderes públicos en la sociedad y en el mercado. En esta atmósfera ideológica se pueden comprender adecuadamente los principios que presiden el Acuerdo General sobre Aranceles Aduaneros y Comercio de 1994 (GATT de 1994), así como el Acuerdo General sobre el Comercio de Servicios (AGCS) del Acuerdo sobre la OMC; y, fundamentalmente, entender la ideología que gobierna la profundización en la integración económica de la Unión Europea, es decir, el paso de la fase de Mercado Común a Unidad Económica Supraestatal y, posteriormente, el Tratado para la Constitución Europea, que tras su fracaso fue sustituido por el Tratado de Lisboa.

La integración económica europea se insertaba ideológicamente en el campo de las constituciones económicas intervencionistas, muy claramente, en sus fases de zona de libre comercio y unión aduanera; probablemente la fase de mercado común se alcanza también con una ideología intervencionista. Ahora bien, el paso a unidad económica supraestatal, con el euro como moneda única, empieza a estar influenciada por las corrientes económicas liberales en boga en esa época, en detrimento de la política económica intervencionista. La siguiente fase, el Tratado de Lisboa surgido de las cenizas del Tratado para la Constitución Europea es seguramente ya otra cosa.

El Tratado de Lisboa fue lo que se pudo salvar del Tratado para la Constitución europea que era el resultado del pacto posible entre, de una parte, los partidarios de una Constitución Federal Europeay, de otra, los defensores de reducir la Unión Europea a una Unidad Económica Supraestatal. Su ideología responde, en opinión muy extendida en Europa, a las corrientes liberales imperantes. Si se analiza su repercusión sobre las constituciones económicas intervencionistas existentes en la mayoría de estados europeos, por ejemplo, a través de la española, se observa una clara reducción del pluralismo político, al quedar muy cercenadas las políticas económicas progresistas e intervencionistas. Se impide así ejecutar mecanismos importantes del Estado Social y se reduce la pluralidad de políticas económicas a aplicar. La reserva al sector público de recursos o servicios esenciales, especialmente los monopolios, no suele estar permitida. Se reconoce la iniciativa pública económica, aunque se incentiva su eliminación. Además, 
esta iniciativa pública debe coexistir con la iniciativa privada y en condiciones de economicidad, es decir, sin privilegios ni ventajas y en duras condiciones de competitividad, lo que impide recibir ayudas o subvenciones públicas, lo que en ocasiones origina su inviabilidad; lo que impediría ciertas intervenciones públicas, reclamadas por el Estado Social, sobre la sociedad y el mercado. La planificación de la actividad económica y la intervención de empresas se abandonan y no se prevén mecanismos de participación de los trabajadores en las empresas. Toda la riqueza del país en sus distintas formas y sea cual fuere su titularidad ya no puede estar subordinada al interés general. Estas políticas económicas, denominadas progresistas, encuentran su acomodo concreto en los artículos 128, 129 y 131de la Constitución española y su aplicabilidad queda temporalmente en suspenso, su efectividad hibernada, mientras España forme parte de la Unión Europea.

Con todo, se debe resaltar que en el caso español, la aplicación de estas políticas más liberales que neoliberales ha llevado a grandes éxitos macroeconómicos. Los principales monopolios estatales se han privatizado y convertido hoy en grandes multinacionales, con tecnología punta mundial en ciertos sectores, como banca y telecomunicaciones, y con una alta productividad.

\section{LA SEGUNDA FASE DE LA GLOBALIZACIÓN: LOS ACUERDOS ENTRE BLOQUES ECONÓMICOS}

En el nuevo orden económico internacional que origina la segunda fase de la globalización hay nuevos actores: los órganos ejecutivos de los acuerdos de integración, potencias económicas y los países emergentes.

Los BRICS o países emergentes son países en vías de desarrollo, que dejan atrás a los subdesarrollados, y se caracterizan por un tamaño territorial igual o superior a la Integración Euro o a EEUU y por sus altas tasas de crecimiento en el PIB durante la última década. Frente a una polarización extrema entre ricos y pobres en los últimos tiempos están creando una clase media significativa, la clase media alta sube con fuerza y los multimillonarios también. De mayor a menor relevancia podemos incluir a China, donde encontramos una constitución económica dual que mantiene la tradicional constitución económica marxista centralizada en paralelo a una constitución económica liberal; su vertiginoso despliegue económico -es ya es segundo exportador mundial tras Alemaniaorigina que sea un actor propio en el nuevo orden económico. Brasil que, además, se encuentra en la integración económica supraestatal más desarrollada de América -fase de unión aduanera en camino a mercado común- Mercosur, que aglutina a Argentina, Uruguay, Paraguay y, recientemente, Venezuela. La India. Rusia, que más que un país emergente es una ex potencia, incluida entre los emergentes por su dimensión territorial y sus exportaciones de petróleo y gas. Sudáfrica es tradicionalmente incluida entre los emergentes, aunque su tamaño y PIB plantean dudas razonables. Hay otros muchos países que no son calificados 
como emergentes por falta de dimensión territorial, como Colombia o Corea del sur, o por su menor tasa de crecimiento como México, aunque se encuentran integrados en zonas de libre comercio o uniones aduaneras.

Cuando en dos mil cinco redacte "Integración económica y reforma constitucional", parecía que tras el fracaso de la OMC en la liberalización comercial multilateral el objetivo de la globalización, es decir, la tendencia de las empresas y los mercados en superar el marco estatal, iba a quedar satisfecha con integraciones económicas supraestatales cada vez más intensas. Ocho años después se puede afirmar que esté era sólo un primer paso. El segundo origina un cambio de actores, los estados ya no son protagonistas con las relevantes excepciones de Estados Unidos y dos emergentes: Rusia y China, el resto de actores son los ejecutivos de las integraciones económicas supraestatales. Esta segunda fase se caracteriza por la firma de acuerdos, tratados y convenios internacionales económicos entre estos actores; por el momento su contenido se limita al libre comercio, el paso siguiente las uniones aduaneras, pero nada obsta a que progresivamente se vaya profundizando como ha sucedido en las integraciones económicas supraestatales. El límite de esta integración está todavía lejos o quizás no: la unidad económica mundial. Este fenómeno de la globalización parece imparable.

Esta segunda fase de la globalización está teniendo consecuencias todavía más importantes sobre el concepto racional normativo de Constitución. Las veremos al tiempo de examinar las ventajase inconvenientes de la globalización y si hay alguna posibilidad de superar éstos.

\subsection{Ventajas de la globalización}

Los modelos de sustitución de importaciones que implicaban el cierre de fronteras a principios de los años noventa del siglo pasado no estaban generando altas tasas de crecimiento. Con la globalización en sus dos fases se buscan las ventajas de la especialización en ciertas industrias y bienes e, incluso, en sectores de ciertas, lo que incrementa las economías de escala con la posibilidad de empleos mejor remunerados al aumentar el volumen de producción y reducirse el precio de los productos.

Una segunda ventaja es la búsqueda de la paz, Estados Unidos estaba convencido de que el proteccionismo había sido una causa de la II Guerra Mundial, de ahí que incentivará en su momento la creación del mercado común europeo; el intercambio comercial intenso y los acuerdos económicos dificultan la guerra.

La tercera es la aparición de nuevos e inmensos mercados que constituyen una oportunidad para las empresas más competitivas; en España es evidente en sectores como la banca, las telecomunicaciones, las constructoras, las energías renovables o la industrial textil. En un primer momento la ventaja parecía sólo para las empresas multinacionales pero empieza a extenderse a medianas y pequeñas empresas y a nuevos sectores productivos. 
Finalmente y sin ánimo exhaustivo, un incremento de la riqueza mundial en paralelo a una redistribución de ésta. Esta ventaja presenta una doble faz, tiene ganadores y perdedores. Entre los primeros se encuentran los Brics y los países en vías de desarrollo que están logrando empleos mejor remunerados, un incremento sustancial de los multimillonarios y la aparición de una importante clase media, frente a la polarización anterior a la globalización entre, de una parte, multimillonarios y clase media alta y, de otra, pobres. También figuran entre los ganadores los multimillonarios de Europa y Estados Unidos. Los segundos o perdedores, entrando ya en los inconvenientes, son las clases medias, especialmente asalariadas, y los desempleados que empiezan a entrar en exclusión social o directamente en la categoría de pobres de Europa y Estados Unidos.

\subsection{Inconvenientes de la globalización}

Las integraciones económicas supraestatales eran la primera etapa de la globalización y en su fase más avanzada dieron lugar a la Integración económica supraestatal euro. Ya se reseñaron como inconvenientes ladesconstitucionalización de las Constituciones económicas, el marco jurídico fundamental de la estructura y funcionamiento de la actividad económica no viene recogido en las constituciones estatales sino en los tratados de la integración. La soberanía popular y el principio democrático se estaban viendo seriamente afectados sino atacados.

La segunda etapa de la globalización, aquella de acuerdos económicos entre diferentes bloques económicos, o preparación para su celebración, es ya probablemente un embate en toda regla al concepto racional normativo de constitución o, cuando menos, a la constitución económica intervencionista y al Estado Social que es su manifestación en Europa. Por esta razón, el papel va a limitar el análisis de los inconvenientes de la segunda fase de la globalización a la Integración Euro.

Las consecuencias constitucionales de esta fase derivan algunas directamente del acuerdo entre bloques económicos y otras, indirectamente, a través de las decisiones que la Integración Euro adopta internamente a resultas del acuerdo entre bloques económicos o en su preparación.

Entre las consecuencias directas destaca que los Tratados de Integración Euro dejan de ser el marco jurídico fundamental de la estructura y funcionamiento de la actividad económica cuando sus órganos ejecutivos firman un acuerdo de libre comercio con otro bloque económico; si en el futuro se tendiese a acuerdos de unión aduanera o mercado común los efectos serían más intensos. En esta primera fase, acuerdo de libre comercio entre bloques económicos, se afecta al principio de unidad económica supraestatal y a su correlato el de unidad de mercado; si se completa la zona de libre comercio, el mercado de mercancías $y$, en menor medida, el de servicios se corresponde con el ámbito territorial de los bloques económicos que han suscrito el acuerdo; ciertas competencias 
ejecutivas y, con intensidad menor, legislativas y judiciales resultan restringidas; si los parlamentos estatales de cada bloque ya tenía dificultades de controlar los convenios suscritos en el interior de la integración económica supraestatal por sus ejecutivos la dificultad se multiplica ahora exponencialmente y está función no ha sido sustituida todavía por el parlamento sobre el ejecutivo de la integración. Las responsabilidades políticas de los gobiernos estatales por el acuerdo entre bloques ni siquiera llegan a plantearse por los parlamentos estatales al menos por el momento. La afección a la constitución económico euro, que lo es materialmente pero no formalmente, resulta mucho más intensa al establecerse una zona de libre comercio con otro bloque económico que cuando se creó la integración europea. En ambos casos, la constitución económica de los estados o de la integración pasa a estar condicionada por las cláusulas del tratado o acuerdo. Sin embargo, los costes de los factores de producción suelen ser bastante más homogéneos en el interior de la zona euro que con el bloque económico que se firma el acuerdo con lo que llegan a resultar afectadas las reglas constitucionales básicas del capitalismo, al punto que podría hablarse hoy de un sistema económico post capitalista. Se incumplen las condiciones de economicidad entre las unidades económicas de los estados que han concluido el acuerdo entre bloques económicos. Las condiciones de economicidad se incumplen en la vertiente de libre competencia entre los agentes económicos al no existir unas condiciones básicas de igualdad entre éstos. Imaginemos un supuesto extremo, firma de un acuerdo económico de la Integración Euro y Mercosur o mejor China, La desigualdad comienza por abismales diferencias salariales, continúa con los impuestos, sigue con la financiación empresarial y la ausencia de costes de protección medioambiental, y termina en la negación de la libertad sindical o la inexistente protección al trabajador y sus derechos constitucionales. En acuerdos entre bloques económicos menos extremos sigue produciéndose una sustancial desigualdad en los costes que soportan las unidades económicas por lo que es difícil sostener todavía que hay una igualdad entre los agentes económicos que garantice una libre competencia que responda a las reglas del capitalismo.

Aun siendo graves las consecuencias constitucionales que derivan directamente del Acuerdo entre bloques económicos todavía parecen mayores las que provienen indirectamente, esto es, a través de las decisiones que el ejecutivo de la Integración Euro adopta internamente a consecuencia del acuerdo entre bloques económicos o pensando en su celebración. No obstante, para afrontarlas debidamente es conveniente una breve reseña de las crisis de 2007 y de la aun no superada de 2010 .

Hay que recordar que desde la creación del Banco Central Europeo y la moneda única el exceso de ahorro de Centroeuropa se transfirió ala periferia de Europa a tipos de interés tan bajos que, en menos de ocho años, estos estados presentaban una colosal deuda privada en manos de familias y empresas, incluidas las bancarias que se endeudaron externamente ante la falta de ahorro interno para atender esa demanda infinita de dinero a bajos tipos de interés, especialmente 
relevante fue el caso de España y de su sector inmobiliario. Al tiempo ese dinero fácil provocó un diferencial de inflación intenso entre los estados de Centroeuropa y los de la periferia con encarecimientos de precios y de los factores de producción, incluidos obviamente los salariales, así como de los gastos presupuestarios y de los prestacionales. El resultado fue una acelerada pérdida de competitividad de estos estados frente a los restantes. En este contexto estalla la crisis mundial de 2007 de naturaleza financiera que trae su origen de políticas ultra liberales desregulatorias, fundamentalmente las hipotecas basura. La desconfianza inundó el mercado financiero ante la ignorancia de los activos tóxicos que acumulaba cada entidad financiera.A gran velocidad el crédito dejo de fluir y se encareció sustancialmente, colocando en una situación muy difícil a familias, empresas y bancos, originando una brusca y profunda recesión. Se puede estimar que la Integración euro no combatió adecuadamente la raíz de la crisis: falta de transparencia sobre los activos financieros para eliminar la desconfianza y restablecer el crédito. En su lugar alentó a los estados a políticas neo keynesianas fundadas en un fuerte incremento del gasto público ante la retracción del sector privado. Estas políticas funcionaron inicialmente e, incluso, permitieron compensar y reactivar débilmente el sector privado, pero no combatieron la raíz de la crisis. Además, originaron un vertiginoso crecimiento del déficit público, fruto de la recesión que reducía los ingresos más los gastos derivados de las políticas keynesianas, lo que provocó los primeros incrementos significativos de la deuda pública. Hasta que en torno a 2010 se hizo presente la segunda crisis, en esta ocasión europea. A la falta de crédito y al incremento de los tipos de interés por la desconfianza sobre los activos tóxicos no solventada plenamente por la Integración Euro se añadió el que la atención se focalizara ahora, además, sobre cómo iban a devolver los países periféricos su colosal deuda privada, lo que se agravaba porque los bancos del sur dependían de las transferencias crediticias de los bancos de Centroeuropa, que este contexto habían dejado de fluir. Se temía con razón que el estrangulamiento de la banca sureña originara conversiones de deuda privada en pública. La tormenta perfecta estaba servida. A la gran deuda privada de los estados del sur venía a sumarse la deuda pública fruto de las conversiones de deuda privada en pública -ayudas para reflotar la banca -, del déficit público, originado por la falta de ingresos por impuestos fruto de la recesión y por el incremento del gasto público, primero por las políticas keynesianas y después por las políticas asistenciales que debieron incrementarse por la recesión. El crédito no sólo dejó de fluir y se encareció para el sector privado sino también para el público, para los estados. El ejecutivo de la Integración Euro respondió lentamente y hoy empieza a pensarse que mal: drásticas reducciones del gasto público y austeridad. Los recortes agravaron la recesión, el déficit no bajaba sustancialmente y la deuda se incrementaba, lo que se ganaba con el recorte de gastos se perdía por la menor recaudación de impuestos ante la caída de la actividad económica, lo que generaba más gastos en prestaciones sociales y en pago de la deuda pública por la elevación de la misma y de los tipos de interés fruto de la creciente desconfianza de los mercados internacionales. En paralelo llego un momento en que algunos estados periféricos 
vieron cerrado el crédito necesario para atender sus gastos presupuestarios y de renovación de su deuda pública por la inexistencia de crédito o por los elevados tipos de interés que el mercado les exigía -Grecia, Irlanda, Portugal- otros estuvieron al borde del abismo -Italia o España-. La integración euro suponía la perdida de la competencia soberana sobre la divisa, la imposibilidad de imprimir dinero, función reservada en exclusiva a un Banco Central Europeo diseñado a imagen y semejanza del Banco Central alemán, el default sobre la deuda pública de estos países y la quiebra estaba servida. La moneda única estaba amenazada. La Integración Euro respondió lenta y contradictoriamente con un default parcial en Grecia y en paralelo con planes de rescate europeo: préstamos de los estados del euro a los países que veían cerrado el crédito, como Grecia, Irlanda, Portugal e, incluso, España. Aunque es este último caso este estado no tenía cerrado el crédito y se trataba exclusivamente de atender el rescate de algunos de sus bancos. Se otorgaron 100.000 millones de euros de línea de crédito de la que sólo se han utilizado 40.000 millones y no parece que España vaya a utilizar el dinero restante del rescate.

Ya se reseñó que la exigencia para entrar en el club euro obligaba a que el déficit público no superara el tres por ciento y la deuda pública el sesenta por ciento del PIB, prácticamente todos los estados incumplieron, pero en los de la periferia con mucha mayor intensidad, como se ha visto. A modo de ejemplo España paso de alumno aventajado al inicio de la crisis con un superávit presupuestario y una deuda pública del 37 por ciento del PIB, a un déficit del 11.2, actualmente el 7 por ciento sin computar el rescate bancario, y una deuda pública del 84,2 en 2012. También se indicó que se preveían mecanismos sancionadores para los incumplidores -multas respecto al producto interior bruto-. Sin embargo, la situación sintetizada de la crisis permite comprender que el ejecutivo de la Integración Euro ha contado con mecanismos más eficaces que las sanciones para imponer los recortes en el gasto público y la austeridad. Los países al borde de la quiebra sólo tenían dos soluciones: abandonar el euro o aceptar los planes económicos diseñados por el ejecutivo de la Unión -Comisión y Consejoa cambio de recibir el rescate en forma de préstamos a bajo tipo de interés, imprescindibles para atender sus gastos, incluso los sueldos de los funcionarios. Estos planes incluyen recortes en el gasto público, reformas estructurales y elevación de impuestos, su implementación ha exigido reformas legales e incluso constitucionales. Su cumplimiento es supervisado por el Consejo, la Comisión y por órganos específicos creados al efecto como la "Troika”. Con esta expresión se conoce al órgano que más sobre el terreno supervisa los planes impuestos a cambio del rescate económico en aquellos casos en que ha intervenido el Fondo Monetario Internacional (FMI); la "Troika" está compuesta por un representante de la Comisión Europea, otro del Banco Central Europeo y, finalmente el del Fondo Monetario Internacional.

El recorte se ha extendido a todo tipo de gastos públicos, primeramente eran lineales afectando a todas las administraciones y departamentos ministeriales, 
para después extenderse progresivamente a las inversiones, a los gastos en mantenimiento, a los sueldos de la clase política y funcionarios, a los pensionistas, plasmándose en fusiones y eliminación de administraciones públicas - caso de Italia y proyectos en España -, despido de funcionarios - Grecia -, alcanzando finalmente los recortes a todo tipo de prestaciones como la dependencia, las prestaciones de desempleo, la educación, incluida la investigación, innovación y desarrollo, y la sanidad.

Las reformas estructurales han exigido implementar medidas legales e incluso constitucionales y han abarcado todo tipo de sectores, estando el procedimiento lejos de finalizar. Entre las más destacadas cabe mencionar la eufemísticamente denominada reforma del mercado laboral que básicamente ha significado un abaratamiento del despido, su facilitación en empresas con pérdidas económicas y la búsqueda de los convenios colectivos de empresas frente a los sectoriales o estatales, conjunto de medidas que básicamente persiguen una reducción de los costes salariales. Una reforma de las pensiones dirigida a retrasar la edad de jubilación e incrementar los años de cotización, esto es, pensiones más bajas y exigencia de mayor edad para el acceso a la pensión. Liberalización y desregulación de numerosos sectores en busca de incrementar la competitividad.

La implementación constitucional europea más destacada, dentro de las reformas estructurales, ha sido sin duda la reforma del artículo 135 de la Constitución española -Eslovenia acaba de aprobarla en mayo de dos mil trece-, previamente incorporada a la Ley Fundamental de Bonn, inducida directamente por el BCE bajo presión extrema de los mercados financieros sobre la deuda pública española. Esta reforma consagra la regla de oro, que no llego a plasmarse en reforma constitucional en EEUU, pese al empuje de Buchanan, pues tras aprobarse por las legislaturas de veintisiete estados no llegó a los dos tercios necesarios. La reforma española que no es plenamente operativa hasta 2020, cuya exposición de motivos reveladoramente apela a la globalización, consagra la estabilidad presupuestaria al afirmar que las Administraciones públicas españolas no podrán incurrir en un déficit estructural, ni en un volumen de deuda pública respecto al PIB que supere los márgenes establecidos por la Unión Europea para sus Estados Miembros, salvo catástrofes naturales, recensión económica o situaciones de emergencia extraordinaria que escapen al control del Estado o perjudiquen considerablemente la situación financiera o la sostenibilidad económica o social del Estado, apreciadas por la mayoría absoluta de los miembros del Congreso de los Diputados. El mismo precepto establece la prioridad absoluta en el pago del capital e intereses de la deuda pública y preveía la que hoy es la Ley Orgánica de Estabilidad Presupuestaria y Sostenibilidad Financiera de 27 de abril de 2012, que traslada los mecanismos de control de la Integración Euro a los Estados Miembros, mutatis mutandis, a la relación entre el poder central y las Comunidades Autónomas, con mecanismos de supervisión y control, así como sancionadores. Aunque al igual que sucede en el ámbito europeo el mecanismo más efectivo sigue siendo la imposibilidad de numerosas Comunidades Autónomas 
de acceder a la financiación de su deuda, lo que les impele a seguir los dictados del poder central o quebrar. No ha habido referencia a los municipios, dado que el artículo $135 \mathrm{CE}$ les exige un equilibrio presupuestario que ya han alcanzado globalmente, quedando ayuntamientos específicos sometidos a control. Sobre esta materia y los temas tratados en este papeles básica la consulta del libro Reforma Constitucional y estabilidad presupuestaria: el artículo 135 de la Constitución española, dirigido por Diego López Garrido, que trae su causa de la Jornadas que se organizaron en Albacete en noviembre de dos mil doce.

El ejecutivo de la Integración Euro no se ha limitado como se señalaba, a operar en el presupuesto sólo sobre los gastos, recortes y ciertas reformas estructurales, sino que ha extendido sus recomendaciones a los ingresos. Llama la atención poderosamente su insistencia en los impuestos indirectos frente a los directos, especialmente en el caso del impuesto sobre el consumo (IVA); también su posición respecto al de Sociedades, sobre el que más adelante algo se dirá. La Comisión ha impuesto en todos los países con mayores problemas sucesivas elevaciones del IVA, tomando como ejemplo España, este impuesto ha pasado de gravar el consumo general en apenas tres años del 16 al 21 por ciento, el reducido que se aplica a ciertos productos sube del 7 al 10, eliminado además algunos de los productos de este tipo que pasan al general del 21 -por ejemplo buena parte de la actividad cultural-, el superreducido, que grava productos de primera necesidad sigue en el cuatro; al tiempo la Comisión impelía a subir los impuestos especiales sobre el alcohol, el tabaco y los carburantes que se encontraban por debajo de la media europea, así como la introducción de impuestos medioambientales de introducción inminente que ya rigen en otros países europeos. España ha ido plegándose a varias de estas recomendaciones y logró retrasar algunas subidas de los indirectos, por ejemplo, logro contener la subida del IVA en un primer momento del 16 al 18 por ciento y del 7 al 8 , a cambio de elevar el impuesto sobre la renta de las personas físicas (IRPF), que ya se sitúa entre los más altos de Europa.

Este conjunto de medidas, con una intensidad sustancialmente menor, se ha ido aplicando a otros Estados miembros con menores problemas de déficit y deuda. Por ejemplo, Francia o, incluso, Holanda. Alemania ha sido la menos afectada, incumple en deuda pero mantiene de momento superávit, probablemente porque ya tuvo su propia crisis y el correspondiente ajuste cuando la periferia nadaba en la abundancia, concretamente bajo la cancillería de Schröder, antes de la llegada de Merkel al poder.

El resultado del conjunto de medidas ha permitido reducciones significativas del déficit, por ejemplo, en España del 11.1 al 7 por ciento del PIB, pero sin poder evitar un importante incremento de la deuda pública. Como se dijo anteriormente, la disminución de los gastos llevaba a una reducción de los ingresos vía impuestos por la recesión y a nuevos gastos para atender los incrementos del pago de la deuda - por su aumento y la elevación de los intereses- y las prestaciones por desempleo. Actualmente, la Integración Euro parece atender a la realidad de 
una segunda recensión, menos intensa pero más prolongada en el tiempo, que se extiende imparable por Europa y a las recomendaciones del FMI y de los economistas más progresistas como PaulKrugman, JosephStiglitz, ralentizando el ritmo del ajuste presupuestario en el tiempo. Quizá esta solución podría haberse aplicado antes en el tiempo si los gobiernos de la periferia hubieran explicado al líder de la Integración Euro que no es lo mismo aplicar estos ajustes en un estado como Alemania que debe más de la mitad de su PIB a la exportación que hacerlo en estados en que dicho porcentaje está en una horquilla tradicional de entre el veinticinco y el treinta por ciento como es el caso de Reino Unido, Francia, Italia y España, aunque este último país ha logrado elevar este porcentaje al 33,1 en el año 2012, situándose sólo por detrás del país germánico en Europa.

Las consecuencias constitucionales de estas medidas difieren entre los estados según su grado de cumplimiento del déficit y del volumen de deuda pública. Si en la fase de unidad económica supraestatal ya se hablaba de una serie afección a la soberanía popular, al principio democrático y de una desconstitucionalización de las constituciones económicas, que originaba una reducción del pluralismo político en materia económica y una hibernación de los preceptos constitucionales que contemplan las medidas más progresistas e intervencionistas en materia económica; ¿qué se podría decir ahora?

Resulta evidente que los estados intervenidos por la Integración Euro a través del plan de rescate y los amenazados por caer en la misma suerte no son estados soberanos, independientemente del concepto de soberanía que empleemos, ni adoptan materialmente decisiones transcendentales con los cánones que exige el principio democrático, ya sea por haber incumplido los requisitos de la integración o simplemente por la crisis. La ausencia de un banco central que les permita imprimir moneda les compele a quebrar, abandonar el euro o someterse a los planes que se han reseñado que aunque les deja un estrecho margen de discrecionalidad no parece compatible con los atributos soberanos de un estado ni con el principio democrático. Mantener que pueden elegir la quiebra y el abandono del euro con serias sospechas de que esta decisión llevaría al caos tampoco parece un argumento que permita sostener la soberanía. La Integración Euro ha tratado de superar su déficit democrático, pese a las reformas, especialmente del Tratado de Lisboa, no parece que pueda defenderse que las relaciones Consejo, Comisión Europea y Parlamento permitan hablar de que la soberanía pérdida por los ciudadanos en al ámbito estatal se recupera en la Integración euro y que las decisiones de la misma respondan al principio democrático. Es más las alternancias de gobiernos de distinto signo ideológico mediante elecciones, más la impuesta en Italia por los mercados - Monti frente a Berlusconi-, en Grecia, Portugal, Italia y España han llevado a algunos con razón a sostener que el principio democrático no consiste en poder cambiar los partidos que sostienen al gobierno sino el contenido de las políticas que éstos ejecutan. Los problemas que se denunciaban en el escrito de 2005 se han visto exponencialmente agravados respecto a la soberanía y al principio democrático. 
El paso de una soberanía y democracia material y formal a una sólo formal no es la única consecuencia constitucional en esta fase que se está sintéticamente describiendo. La desconstitucionalización de las Constituciones económicas se ha completado totalmente al entrar de lleno en materia presupuestaria, tanto en la vertiente de ingresos como en los gastos.

La desconstitucionalización o más precisamente el quebrantamiento de la Constitución -incumplimiento reiterado de normas constitucionales sin afectar a su validez-, en terminología de Schimitt, ya no se limita al campo económico sino que comienza a afectar seriamente al conjunto del ordenamiento constitucional, incluidos sus principios y valores, señalados por el Tribunal Constitucional alemán, con razón, como límite infranqueable. El Estado Social, sus mandatos a los poderes públicos y sus derechos sociales se ven seriamente afectados cuando no atacados por los planes diseñados por el ejecutivo de la Integración Euro.

Al quebrantamiento de preceptos constitucionales tampoco escapan las bases del sistema fiscal, como la contribución de todos al sostenimiento de los gastos públicos de acuerdo con su capacidad económica, mediante un sistema tributario justoinspirado en los principios de igualdad y progresividad. Los poderes públicos estatales se ven impotentes para aplicar este mandato constitucional a las grandes fortunas que fácilmente pueden eludir cualquier gravamen gracias a la libre circulación de capitales; en España es ilustrativo el caso de las sociedades de inversión de capital variable, denominadas Sicav, que pagan en torno al 1 por ciento frente a una horquilla entre el 21 y el 27 de cualquier ciudadano o un 25 de las pequeñas y medianas empresas o el 30 de las grandes. Se incrementan los impuestos indirectos a niveles que impiden la progresividad del sistema, en detrimento de los directos, especialmente relevante es el caso del impuesto de Sociedades. A modo de ejemplo en España este tributo tiene un tipo legal para grandes empresas del 30 pero tras operar la ingeniería fiscal el tipo real se sitúa entorno al 17; algo similar sucede con las pequeñas y medianas empresas sometidas a un tipo legal de 25 . El resultado es más escandaloso si se compara el tipo efectivo sobre los beneficios de las empresas, que es lo realmente perseguido por la figura fiscal, en 2006 era del 20 por ciento y en 2010 del 9.4, tras algunas reformas realizadas por el gobierno de Rajoy subió en 2011 al 11.6. No acaba aquí el vaciamiento de los principios constitucionales impositivos, pues cuanto mayor es la empresa, más multinacional, menos paga, el tipo efectivo sobre beneficios de las grandes empresas que consolidan balances se sitúa en el entorno del 5, lo que representa una auténtica competencia desleal frente a otras empresas menores y afecta a la propias condiciones de economicidad del capitalismo. En 2010 los grupos consolidados pagaron 4500 millones por un beneficio de 90.000 y las empresas individuales 10.529 millones frente a unos beneficios de 67.000.Estos datos provienen de la propia Agencia Tributaria española y han sido elaborados por Manuel Lago en un interesante y revelador trabajo. En realidad, el sistema tributario a los ojos del ejecutivo de la Integración Euro ya no se inspira en los referidos principios constitucionales sino en su mayor o menor eficiencia económica que viene marcada por la globalización. 
Obviamente, la situación entre los Estados Miembros es muy diversa en función del grado de incumplimiento de la cifras de déficit y deuda. Por ejemplo, Holanda y especialmente Francia presentan estas mismas consecuencias constitucionales aunque con menor intensidad. Alemania es prácticamente el único estado de la Integración Euro que pese a incumplir en el nivel de deuda pero gracias a un superávit presupuestario no sufre prácticamente consecuencias constitucionales del proceso de globalización, de momento; aunque no es inmune a sus consecuencias como se demuestra, por ejemplo, con el elevado número de alemanes que subsiste con los "minijobs", que tiene salarios de alrededor de cuatrocientos euros, por debajo de los 528 euros de salario medio en Shanghái -240 el de los habitantes urbanos de China- y de los 498 de sueldo medio de los trabajadores en paridad de poder adquisitivo en China.

Finalmente destacar cómo en la Integración Euro aparece un nuevo problema con la denominada crisis de la deuda. En un tono no demasiado elevado se denuncia como están resultado afectadas las condiciones de economicidad del sistema capitalista no sólo de las unidades económicas de la zona euro, respecto a las foráneas, como ya se ha reseñado, sino en el interior de la zona. Las empresas de la zona están viendo afectadas las condiciones de igualdad en el ejercicio de la actividad económica, en definitiva la libre competencia, al ser excesivamente dispares los costes de financiación de las empresas. Los diferenciales en el pago de la deuda entre estados se trasladan automáticamente a las empresas que tienen su sede en los estados que más diferencial pagan. Bien podrían preguntarse a la multinacional Telefónica sobre cómo ha tenido que ceder en su lucha por el liderazgo mundial en telefonía frente a la alemana Vodafone y América Móvil del mexicano Carlos Slim.

Con razón podría sostenerse que estas consecuencias constitucionales no vienen originadas indirectamente por la globalización y los Acuerdos entre bloques económicos sino que son consecuencias directas e indirectas de la Integración Euro. Podría alegarse que ha sido exclusivamente los altos déficits presupuestarios, la elevada deuda primero privada y luego pública la que ha llevado a los países periféricos de Europa a esta situación y que no cabe otra política que la dictada por el ejecutivo de la Integración Euro para que los mercados siguieran prestando. También podría señalarse que la política de austeridad depende de una concepción germánica de penitencia por los excesos cometidos en la periferia en los años de bonanza, impuesta dado el rol de liderazgo absoluto de Alemania en la Integración Euro. Aquí se va a sostener, sin embargo, que estas políticas son consecuencia indirecta fundamentalmente de la globalización y de los Acuerdos entre bloques económicos. El Reino Unido y Estados Unidos demuestran, por sus cifras macroeconómicas iguales cuando no peores en déficit y deuda que España o Italia, que otra política diferente a la austeridad era posible. Lo que se piensa que realmente ha sucedido es que Alemania en su liderazgo de la Integración Euro tomo conciencia de la imposibilidad de que la zona euro compitiera en el mundo de la globalización, en los acuerdos entre bloques económicos y actuó 
en consecuencia. Tras poner su casa en orden con la crisis que lidió Schröder, aprovechó los elevados incumplimientos en déficit y deuda, los consecuentes problemas de financiación de la deuda y la transferencia por los Estados miembros al BCE de la competencia para emitir moneda, para imponer los ajustes en la Integración Euro, no por moralismo, sino para poner en forma a esta integración económica y permitirle estar en condiciones de competir con los otros bloques económicos en el nuevo mundo globalizado. Es lo que se está denominado devaluación interna al no poder devaluar una inexistente moneda propia Esta tesis que se estima evidente, encuentra un apoyo adicional en el impuesto de sociedades. Ya dijimos que algo diríamos más adelante y es el momento. Se señalaba lo sorprendente que resulta el empeño de la Integración Euro en subir el impuesto sobre el consumo y su despreocupación sobre el de Sociedades -aunque en marzo de dos mil trece se vuelve el foco al mismo- , un 21 en España el primero cerca de la media comunitaria que conoce tipos del 25, mientras no llega al 12 en España el tipo efectivo del segundo sobre beneficios. Se trata de una política ultra liberal o más bien, como se estima, una forma de competir las grandes empresas de la zona euro frente a las del resto del mundo, piénsese en lo que se dijo sobre un tipo efectivo del impuesto de sociedades de las multinacionales del 5. Sus efectos son devastadores sobre la justicia tributaria pero resultan en cambio muy eficaces en la competitividad de la globalización. El impuesto sobre el consumo afecta a las empresas euro y a las foráneas, el de sociedades sólo a las radicadas en la zona euro. La disminución de los tipos efectivos en el de sociedades en paralelo a la elevación del impuesto sobre el consumo no es casual en modo alguno.

Junto a los inconvenientes ya reseñados dela globalización hay que destacar complementariamente también el descontrol de gigantescos flujos financieros y el peligro real de sustitución de la economía real por la financiera fruto de la libre circulación de capitales. El poder económico ya no está subordinado al poder político como era propio del concepto racional normativo de constitución; la soberanía del estado y la democracia están desapareciendo en algunos estados sin encontrar su reflejo en estructuras políticas supraestatales. El nuevo orden económico internacional podría definirse como post capitalista al no responder a las reglas clásicas, especialmente al principio de economicidad, lo que directamente origina cierre y deslocalización de empresas o de partes significativas del proceso de producción de éstas; disminuciones salariales en Europa y Estados Unidos; incrementos desconocidos hasta el momento del número de desempleados con tasas de desocupación juvenil en varios estados en torno al cincuenta por ciento, lo que lleva a hablar con razón del miedo a la pérdida de una generación; un serio peligro al Estado Social y a su constitución económica intervencionista; creciente disminución de las clases medias estadounidenses y europeas y buena parte de la que subsiste es la no asalariada que se mantiene con reducciones de impuestos o evasión fiscal. Con todo lo más grave que está sucediendo es una profunda deslegitimación de numerosos sistemas fundados en el concepto racional normativo de constitución que amenazan de no frenarse con el orden social que conocemos. 


\section{HAY REACCIÓN POSIBLE A LOS INCOVENIENTES DE LA GLOBALIZACIÓN EN EL ÁMBITO CONSTITUCIONAL}

Si las hipótesis que en este papel se están manejando tuvieran algo de acertado, lo que sólo podría confirmarse mediante un estudio interdisciplinar más profundo, se habría dado un pequeño paso a la solución del problema, que no es otro que la detección del mismo.

No parece viable por irreal pretender acabar con la globalización. Los inconvenientes que gran parte de las sociedades de Estados Unidos y Europa están sufriendo se tornan en grandes ventajas para sectores minoritarios de las mismas, precisamente las que detentan el poder económico que se está imponiendo al poder político. Esas mismas élites también se benefician en el resto del mundo, al igual que la mayor parte de sus sociedades, incluidas las clases medias y bajas, especialmente en los países emergentes y en los estados en vías de desarrollo que no merecen esa calificación por falta de dimensión territorial y de volumen de PIB. Lo avanzado del proceso convierte en quimera su reversión; no son ya sólo las grandes multinacionales europeas y estadounidenses, con cientos de millones de accionistas a sus espaldas, las que dependen totalmente de la globalización para su propia subsistencia sino que cada vez más el proceso se extiende a medianas y pequeñas empresas. La otra opción que se ha apuntado como solución para los países periféricos de Europa es el abandono de la divisa euro y la recuperación de las competencias cedidas al BCE, en definitiva, una disminución de la integración supraestatal que permita recuperar la soberanía y el principio democrático y, fundamentalmente, recurrir a devaluaciones de las nuevas monedas para recuperar la competitividad en el mundo de la globalización por una vía menos dolorosa que la devaluación interna. Esta hipotética solución plagada de incertidumbres y que probablemente conduciría al caos a corto y medio plazo, parece inviable para la mayor parte de los estados. También lo parece en España, pese a los cantos de sirena provenientes de partes del mundo anglosajón que no dudan en alentar esta posibilidad, más basada en la privilegiada relación española con Iberoamérica que en el tamaño territorial y el PIB de la madre patria. Esta solución cuenta con el ejemplo del Reino Unido y su relación con la comunidad anglosajona y que aunque aún no ha demostrado su capacidad de pervivencia en el mundo globalizado ignora la importante diferencia que existe entre no entrar en el euroy salir de la divisa única. Con todo, no es lugar aquí para analizar detenidamente estas dos posibles soluciones, por espacio y conocimientos; no obstante, se albergan algo más que dudas razonables respecto a las respuestas que pueda aportar la ciencia económica en orden a iniciar un camino tan incierto.

Desde la ciencia constitucional la única solución que sin demasiado optimismo se atisba parece provenir de una de las dos tendencias que se enfrentaron en el Tratado para la Constitución europea. Es necesaria una victoria de los partidarios de un estado federal frente a los defensores de convertir la 
integración europea en una zona de libre comercio. Es imprescindible que las fuerzas de izquierda y en especial los socialistas europeos en alianza ideológica con la democracia cristiana renana recuperen la idea de una Europa integrada no sólo económicamente sino políticamente, como único instrumento con musculo suficiente para intentar combatir no ya, como se pensaba, al ultra liberalismo sino al post capitalismo. Frente a la pérdida en numerosos Estados Miembros de la Integración Euro de la soberanía popular y del principio democrático, frente a la derrota de la constitución económica intervencionista y la afección a principios y valores nucleares de estos ordenamientos constitucionales, frente al jaque al Estado Social y a sus mandatos a los poderes públicos y derechos sociales sólo cabe la creación de un Estado Federal Europeo.

Una Constitución Federal Europea de mínimos, que contemple las principales cuestiones que están sobre la mesa. La atribución al pueblo europeo de la soberanía popular. La proclamación de una Estado Federal, Social, Democrático y Constitucional de Derecho. La constitucionalización de la dignidad de la persona como fundamento del orden político y de la paz social, así como su concreción en un catálogo de derechos fundamentales análogo a los contenidos en las principales constituciones europeas. La constitucionalización de los principales derechos sociales y la garantía de su ejercicio en condiciones básicas de igualdad para todos los europeos, así como de los principales mandatos a los poderes públicos que son consecuencia del Estado Social. Un incremento sostenido de los gastos en investigación, innovación y desarrollo debe plasmarse en el texto constitucional para poder competir en el nuevo orden económico internacional. La creación de una agencia tributaria europea; la reforma y armonización de los principales impuestos europeos que garantice la igualdad y progresividad de todas las rentas, equiparando a partir de ciertos niveles - para no desincentivar el ahorro- las rentas del trabajo con las del capital; la imposición de tasas a las transacciones financieras, la lucha contra el fraude fiscal, los paraísos fiscales y la ingeniería financiera de las grandes empresas. El establecimiento de una democracia representativa de partidos que responda a la tradición europea del último siglo, pero que, para hacerla efectiva al tiempo que combate su creciente deslegitimación, consagre la democracia interna mediante la exigencia de elección directa por los afiliados de los partidos de sus candidatos a parlamentarios, al tiempo que garantiza mediante el recurso de amparo constitucional el derecho de participación política directa en el interior del partido en lo concerniente a los derechos que las leyes otorgan a estos militantes. Un sistema parlamentario de gobierno, con una cámara en representación del pueblo europeo y otra en representación de los estados. La ordenación de las bases de la Administración Europea. La regulación de la estructura y funcionamiento básico de la actividad económica, esto es, la consagración de la Constitución económica intervencionista y, probablemente, por imperativo de Alemania el principio de estabilidad presupuestaria y estrictos límites al déficit estructural; la constitucionalización y publicación del Banco Central Europeo; la titularidad en la emisión de deuda pública y la asunción del 
sesenta por ciento de la de los Estados Miembros; así como la Unión Bancaria con la garantía de los depósitos bancarios de la zona euro; finalmente en el campo económico deben constitucionalizarse fórmulas que garanticen que los acuerdos y convenios internaciones que concierte la Europa Federal con otro bloque económico sólo podrán realizarse si se garantiza una equiparación progresiva de las condiciones económicas básicas del capitalismo: progresiva homologación de salarios, impuestos, costes medioambientales y la garantía de la libertad sindical y los derechos de los trabajadores, así como su protección. Por último, en línea con la tradición constitucional europea se debe contemplar un sistema de justicia constitucional concentrado y las cláusulas de reforma constitucional.

La ciencia constitucional hace mucho tiempo que está sobre los relevantes problemas que la integración supraestatal europea origina al concepto racional normativo de Constitución y son innumerables los estudios publicados en la materia, especialmente en Alemania, así como la relevante jurisprudencia de su Tribunal Constitucional; en España ocupan un lugar prominente los publicados por el doctor López Castillo. El maestro Rubio Llorente ya se ocupó de los efectos que la Ley Orgánica de Estabilidad Presupuestaria y Sostenibilidad Financiera, una consecuencia constitucional más de la Integración Euro, origina sobre las relaciones entre el Poder central y las Comunidades Autónomas en un seminario de los que periódicamente celebra su escuela en la Universidad Autónoma de Madrid. Hace escasas semanas el doctor Rubio, en su discurso de aceptación del Honoris causa que le fue conferido por la Universidad de Valladolid, planteaba como uno de los tres centrales problemas del constitucionalismo español la incidencia de la Integración Euro en nuestro ordenamiento constitucional. En su discurso mostraba la preocupación que en Estados Unidos despierta el problema de la globalización, como demuestra el reciente libro de Rodik, que observa un trilema entre lo que podríamos traducir libremente como soberanía, democracia e integración y su interdependencia y considera inviable un incremento de las tres, así entre las varias opciones ve en una disminución de la integración la posibilidad de incrementar el contenido del principio democrático. En este libro el catedrático de Harvard estima que la Integración Euro quizás pueda combatir los mayores inconvenientes de la globalización. El profesor Rubio se muestra más bien pesimista respecto a esta afirmación.

No es seguro que una Constitución Federal europea como la propuesta pueda preservar el concepto racional normativo de Constitución y al estado social, que tiene en Europa su única manifestación solvente; acabar con la deslegitimación progresiva que hoy se vive en buena parte de Europa; y ser una respuesta adecuada a los inconvenientes que la globalización genera. A esta falta de optimismo se deben añadir las dificultades de alcanzar una constitución europea. Es dudoso que la población de varios estados pudiera estar a favor del objetivo. Obviamente más difícil todavía en los estados que menos han sufrido los ajustes y donde menos afectadas han resultado sus constituciones. Y qué decir de Alemania. A las dificultades impuestas por la jurisprudencia del 
Tribunal Constitucional alemán, algunas tan relevantes como su afirmación de la inexistencia de un demos europeo, hay que añadir el obstáculo de convencer al pueblo alemán sobre la necesidad de esa constitución. Como conseguirlo cuando no ha sufrido las penosas consecuencias de la política de austeridad, que tan bien conocen los países periféricos de Europa, gracias a la anticipación de sus ajustes y a la fortaleza de sus exportaciones. Cómo convencer al estado que no ha visto afectada su soberanía, su principio democrático y, prácticamente, apenas alterado su modelo económico y su Estado Social; al estado que se puede permitir paralizar decisiones del ejecutivo de la Integración Euro hasta que se pronuncie su parlamento o su Tribunal Constitucional decida sobre el acomodo de la medida europea que se pretende adoptar a su Ley Fundamental.

\section{NOTA}

1 El presente trabajo es la base del proyecto de investigación financiado por el Ministerio de Economía de España DER2013-48327-C3-1-R: Constitución y Mercado en la crisis de la integración económica europea. El autor del trabajo lidera el grupo de investigación, actuando como grupo coordinador la Universidad de Castilla La Mancha y como proyectos coordinados la Universidad Pablo de Olavide de Sevilla y la Universidad de Deusto.

\section{Referencias Bibliográficas}

ALBERTÍ ROVIRA, Enoch, “La constitución económica de 1978: Reflexiones sobre la proyección de la Constitución sobre la economía en el XXV aniversario de la Constitución española, Revista Española de Derecho Constitucional, núm. 71, 2004.

ÁLVAREZ CONDE, Enrique y SOUTO GALVÁN, Clara, La constitucionalización de la estabilidad presupuestaria, Instituto de Derecho Público de la Universidad Rey Juan Carlos, Madrid, 2012.

ASENJO, Óscar de Juan, La Constitución Económica española, Centro de Estudios Políticos y Constitucionales, Madrid, 1984.

BASSOLS COMA, Martín,Constitución y sistema económico, Tecnos, Madrid, 1985.

“La Constitución económica”, Revista de Derecho Político, núm. 36, 1992.

BREWER-CARIAS, Allan R., "Las implicaciones constitucionales de la integración económica regional", en el libro El derecho venezolano a finales del siglo XX, Biblioteca de la Academia de las Ciencias Políticas y Sociales, Caracas, 1998,

"Las exigencias constitucionales de los procesos de integración y la experiencia latinoamericana”, en Congreso de Academias Iberoamericanas de Derecho, Córdoba, 1999.

CASAS BAAMONDE, María Emilia, "El Gobierno económico de la Unión Europea y el Estado Social", en el libro Reforma constitucional y estabilidad presupuestaria: El artículo 135 de la Constitución española, Centro de Estudios Políticos y Constitucionales, Madrid, 2013. 
DE CABO MARTÍN, Carlos, "Constitucionalismo del Estado Social y Unión Europea en el contexto globalizados”, Revista de Derecho Constitucional europeo, núm. 11, 2009.

GARCÍA GUERRERO, José Luis, “Integración económica y reforma constitucional”, en el libro colectivo: Visión y análisis comparativo de reformas constitucionales en Iberoamérica, Senado de la República Dominicana, Santo Domingo, 2005. 2014.

. La publicidad. Fundamentos y límites constitucionales, Tirant Lo Blanch, Valencia,

GARCÍA PELAYO, Manuel, “Consideraciones sobre las cláusulas económicas en la Constitución”, Obras completas, Tomo III, Centro de Estudios Políticos y Constitucionales, Madrid, 1992.

GARCÍA ROCA, Javier, El principio de estabilidad presupuestaria y la consagración constitucional del freno al endeudamiento", en el libro Reforma constitucional y estabilidad presupuestaria: El artículo 135 de la Constitución española, Centro de Estudios Políticos y Constitucionales, Madrid, 2013.

JACQUES, Martin, When China rules the world. The end of the western world and the birth of a new global order, Penguin, Nueva York, 2009.

KEOHANE, Robert O., MACEDO, Stephen y MORAVCSIK, Andrew, "DemocracyEnhancing Multilateralism”, International Organization, núm. 63, 2009.

LAGO, Manuel, "El impuesto de sociedades, principal responsable de la crisis fiscal española”, Estudios de la Fundación, núm. 59, 2012.

LÓPEZ CASTILLO, Antonio, Constitución e Integración: el fundamento constitucional de la integración supranacional europea en España y en la RFA, Centro de Estudios Constitucionales, Madrid, 1996.

. "De integración y soberanía. El Tratado sobre la Unión Europea ante la Ley Fundamental alemana. Comentario a la sentencia Maastricht del Tribunal Constitucional Federal alemán de 12 de octubre de 1993", Revista Española de Derecho Constitucional, núm. 40, 1994.

. La Constitución de Europa a debate: Estudios sobre el complejo constitucional de la Unión, Tirant Lo Blanch, Valencia, 2004.

."Presupuestos políticos y jurídicos: ¿Si ya hay Tratados constitucionales, para qué una Constitución europea?, Noticias de la Unión Europea, núm. 250, 2005.

. "La Unión Europea "en constitución” y la Constitución estatal en espera de reformas: a propósito de la DTC 1/2004, de 13 de diciembre de 2004”, Teoría y Realidad Constitucional, núm. 15, 2005.

. "Alemania en la Unión Europea a la luz de la "Sentencia-Lisboa" de 30 de junio de 2009, del Tribunal Constitucional Federal alemán, Revista Española de Derecho Constitucional, núm. 87, 2009. 
. “Constitución y constitucionalización en la Europa de entre siglos”, Derecho Constitucional europeo. Actas del VIII Congreso de la Asociación de Constitucionalistas de España, Tirant lo Blanch, Valencia, 2011.

. "La tentativa de respuesta europea a la crisis del Euro y de la Deuda (griega) al amparo del Tribunal Constitucional Federal alemán. Comentario sucinto de la sentencia del 07/09/2011 (2 brv 987/10, 1485/10, 1099/10)", Revista de Derecho Comunitario Europeo, núm. 39, 2011.

. LÓPEZ GARRIDO, Diego, Reforma constitucional y estabilidad presupuestaria: El artículo 135 de la Constitución española, Centro de Estudios Políticos y Constitucionales, Madrid, 2013.

.Apuntes para un estudio sobre la constitución económica", Revista del Centro de Estudios Constitucionales, núm. 15, 1993.

MARTÍNEZ LAGO, Miguel Ángel, “Constitucionalización del principio de estabilidad presupuestaria en la Unión Europea y en España. La Ley de Estabilidad Presupuestaria y Sostenibilidad Financiera", en el libro Reforma constitucional y estabilidad presupuestaria: El artículo 135 de la Constitución española, Centro de Estudios Políticos y Constitucionales, Madrid, 2013.

MEDINA GUERRERO, Manuel, "La reforma del art. 135 de la Constitución”, Teoría y Realidad Constitucional, núm. 29, 2012.

POSNER, Eric, The perils of global legalism,Univ. of Chicago Press, Chicago, 2009.

PRATS, Eduardo Jorge, Derecho Constitucional, vol. I y II, IusNovum, Santo Domingo, 2010 y 2012.

RODRÍGUEZ BEREIJO, Álvaro, "La reforma constitucional del artículo 135 y la crisis financiera del Estado”, Otrosí, núm. 11, 2012.

.“Constitución económica y Constitución Fiscal”, en el libro Reforma constitucional y estabilidad presupuestaria: El artículo 135 de la Constitución española, Centro de Estudios Políticos y Constitucionales, Madrid, 2013.

ROBERT Z. Lawrence, Regionalism, multilateralism and deeper integration, Brookings Institutions, Washington DC, 1996.

RODRIK, DANI, La paradoja de la globalización (Democracia y el futuro de la economía mundial), Antoni Bosch Editor, Barcelona, 2012.

SERRANO PÉREZ, Ma Mercedes, "La Constitución económica europea y la transformación operada en el sistema económico interno en el Estado Social”, en el libro Reforma constitucional y estabilidad presupuestaria: El artículo 135 de la Constitución española, Centro de Estudios Políticos y Constitucionales, Madrid, 2013.

SLAUGHTER, Anne Marie, A new world order, Princenton University, 2004. 
TAJADURA TEJADA, Javier, "La crisis de los derechos sociales en el contexto de la mundialización", Nuevas Políticas Públicas. Anuario Multidisciplinar para la modernización de las Administraciones Públicas, núm. 2, 2006.

. "Reforma constitucional e integración europea", Claves de la Razón Práctica, núm. 216, 2011.

. VIZIANO PASTOR, Roberto, "Problemas de legitimidad constitucional de las integraciones supranacionales", Cuadernos Constitucionales de la Cátedra Fadrique FurióCeriol, núm. 67-68, 2009. 


\section{Resumen}

Este artículo trata de la cuestión del modelo constitucional tradicional que contiene, en cierto modo, un contenido similar en la mayoría de los Estados democráticos y su relación con el fenómeno de la integración económica supranacional y la globalización, debatir las ideas de un modelo constitucional propuesta universales propuestos por algunas corrientes doctrinales.

Palabras-clave: Constitución. Integración económica. Globalización. 


\title{
AS INTEGRAÇÕES ECONÔMICAS SUPRANACIONAIS E OS ACORDOS ENTRE BLOCOS ECONÔMICOS, EM SUMA, A GLOBALIZAÇÃO COMO UM ÚLTIMO EMBATE AO CONCEITO RACIONAL NORMATIVO DE CONSTITUIÇÃO.
}

\begin{abstract}
Resumo
O presente artigo trabalha a questão do modelo constitucional tradicional que contém, de certa forma, conteúdo semelhante na maioria dos Estados democráticos e sua relação com o fenômeno de integração econômica supraestatal e a globalização, debatendo as ideias de uma proposta de universalização do modelo constitucional, proposto por algumas correntes doutrinárias.
\end{abstract}

Palavras-chave: Constituição. Integração económica. Globalização 


\title{
THE SUPRANATIONAL ECONOMIC INTEGRATIONS AND THE AGREES BETWEEN ECONOMIC BLOCKS, IN SHORT, THE GLOBALIZATION AS A LAST EMBATE TO THE RATIONAL NORMATIVE CONCEPT OF CONSTITUTION
}

\begin{abstract}
The present article works the question of the traditional constitutional model that contains, in some way, similar content in the majority of democratic States and its relation with the supranational economic integration phenomenon and the globalization, debating the ideals of a proposal of universalization of the constitutional model, proposed by some doctrinal currents.
\end{abstract}

Keywords: Constitution. Economic integration. Globalization. 